\title{
PERANCANGAN DAN ANALISIS PERFORMA POMPA HIDRAM UNTUK MEMENUHI KEBUTUHAN AIR BERSIH DI DUSUN BELANG TLOGOLELE SELO BOYOLALI
}

\author{
Deni Andriyansyah, Yuyun Estriyanto, Danar Susilo Wijayanto \\ Program Studi Pendidikan Teknik Mesin, Jurusan Pendidikan Teknik Kejuruan, FKIP, UNS \\ Kampus UNS Pabelan Jl. Ahmad Yani 200, Surakarta, Telp/ Fax(0271) 718419 \\ Email : andriyansyah.d@gmail.com
}

\begin{abstract}
This research aimed to: (1) determine the daily water needs of Belang population, (2) designing hydram pump installation based on water needs and geographical conditions of Belang village, (3) study the performance and efficiency of the hydram pump, (4) study the role of the hydram pump to fulfill the daily water needs of Belang population. This study was based on Research and Development ( $R \& D)$. It developed hydram pump installation to fit the topography of Belang village so it can work optimally. The pump was tested by varying waste valve length at $20 \mathrm{~mm}, 25 \mathrm{~mm}, 30 \mathrm{~mm}$ and $35 \mathrm{~mm}$; and waste valve ballast at 0 grams, 250 grams, 500 grams and 750 grams. Data collection was performed three times for each variation. Hidram pump performance was determined by the efficiency and the volumetric discharge of water produced during the pump operation. Hydram pump was designed based on standard of the daily water needs which reachs 13650 liters/ day for 195 Belang's people. In this study, hydram pump has some parameters. They are 4,5 meters of supply height, 80 meters of delivery height, 4 inches of pump body diameter and 1 inch of delivery pipe. Based on the tests that have been conducted, the highest efficiency of the hydram pump shown at $30 \mathrm{~mm}$ of waste valve length and 250 grams of waste valve ballast $(\eta=0.486652$, $q=6.746969 \mathrm{~L} / \mathrm{min})$. The maximum volumetric discharge was presented at $35 \mathrm{~mm}$ of waste valve length and 750 grams of waste valve ballast $(q=7.522211 \mathrm{~L} / \mathrm{min}, \eta=0.380989)$. Hydram pump performance could fulfill the water needeed in Belang Village until medium term maintenance level. They could use the water for drinking, cooking, bathing, washing, until cleaning home by 9750 liters/ day.
\end{abstract}

Keywords: hydram pump, pump designing, pump performance, pump efficiency, Tlogolele Selo Boyolali

\section{PENDAHULUAN}

Indonesia merupakan negara kepulauan yang dua pertiga bagiannya berupa perairan. Menurut data P3DI dalam Prihatin (2013), Indonesia dengan cadangan air mencapai 2.530 $\mathrm{km}^{3} /$ tahun atau setara dengan $15.500 \mathrm{~m}^{3}$ per kapita per tahun, termasuk dalam salah satu negara yang memiliki cadangan air terkaya di dunia. Angka tersebut jauh di atas ketersediaan air rata-rata di dunia yang hanya $8.000 \mathrm{~m}^{3}$ per tahun. Meskipun begitu, Indonesia masih mengalami kelangkaan air bersih, terutama di kota-kota besar. Menurut Pakar hidrologi dari Universitas Indonesia, Jakarta mengalami krisis air bersih dan saat ini kondisinya semakin parah. Jakarta memerlukan sekitar 26.938 liter air per detik, namun yang tersedia hanya 17.700 liter air per detik. Berdasarkan laporan Kelompok Kerja Air Minum dan Penyehatan Lingkungan Indonesia, ketersediaan air di Pulau Jawa hanya $1.750 \mathrm{~m}^{3}$ per kapita per tahun pada tahun 2000 dan akan terus menurun hingga $1.200 \mathrm{~m}^{3}$ per kapita per tahun pada tahun 2020. Padahal standar kecukupan minimal ketersediaan air adalah $2.000 \mathrm{~m}^{3}$ per kapita per tahun.
Berdasarkan data Kementerian Kesehatan 2010 dalam Cahyadi (2011), penduduk Indonesia yang bisa mengakses air bersih secara optimal baru 36,6 persen. Lima provinsi di Indonesia yang jumlah penduduknya semakin sulit mengakses air bersih, yaitu DKI Jakarta, Kalimantan Barat, Gorontalo, Jawa Timur, dan Kalimantan Tengah. Kondisi terparah justru terjadi di DKI Jakarta. Hal yang berbeda dapat diamati ketika musim penghujan tiba. Daerah yang sebelumnya rawan krisis air berubah menjadi daerah rawan banjir. Demikianlah kondisi beberapa daerah di Indonesia, kekeringan di musim kemarau dan banjir di musim penghujan yang berarti bahwa sumber daya air belum terdistribusi secara seimbang. Maka dari itu, diperlukan sebuah metode eksplorasi sumber daya air yang berkelanjutan untuk menjamin keberadaan air ketika dibutuhkan.

Hal serupa juga dialami oleh Dusun Belang yang terletak di sisi barat laut Gunung Merapi serta mempunyai topografi berupa perbukitan. Penduduk biasanya dapat memanfaatkan mata air yang terdapat di bawah bukit untuk 
memenuhi kebutuhan air sehari-hari, baik untuk keperluan pertanian maupun kebutuhan rumah tangga. Masalah kekeringan melanda penduduk ketika musim kemarau tiba. Penduduk tidak dapat memperoleh air karena sumber mata air terdekat yang biasa digunakan juga mengalami kekeringan. Hal ini mengakibatkan penduduk Dusun Belang harus mencari sumber air yang letaknya lebih jauh serta melintasi jurang untuk mendapatkan air. Sumber air yang masih produktif pada saat musim kemarau juga harus dibagi dengan beberapa dusun yang ada di sekitarnya. Mayoritas penduduk Dusun Belang berprofesi sebagai petani. Penduduk biasanya menanam komoditas yang tidak memerlukan banyak air dalam perawatannya jika musim kemarau tiba. Air yang diambil dari mata air biasanya hanya cukup untuk memenuhi kebutuhan memasak dan MCK.

Dusun Belang mempunyai topografi yang cocok untuk penerapan pompa hidram. Pompa hidram adalah suatu alat yang digunakan untuk memompa dengan cara menaikkan air dari

\section{LANDASAN TEORI}

Hidraulik ram (hidram) merupakan suatu alat yang digunakan untuk menaikkan air dari tempat yang rendah ke tempat yang lebih tinggi secara otomatis dengan memanfaatkan energi yang berasal dari air itu sendiri. Komponen pompa hidram cukup sederhana tetapi efektif digunakan dalam kondisi yang sesuai dengan syarat-syarat yang diperlukan untuk operasinya. Selama pompa hidram bekerja, tekanan air dinamik yang ditimbulkan memungkinkan air untuk mengalir dari tinggi vertikal (head) yang rendah ke tempat yang lebih tinggi.

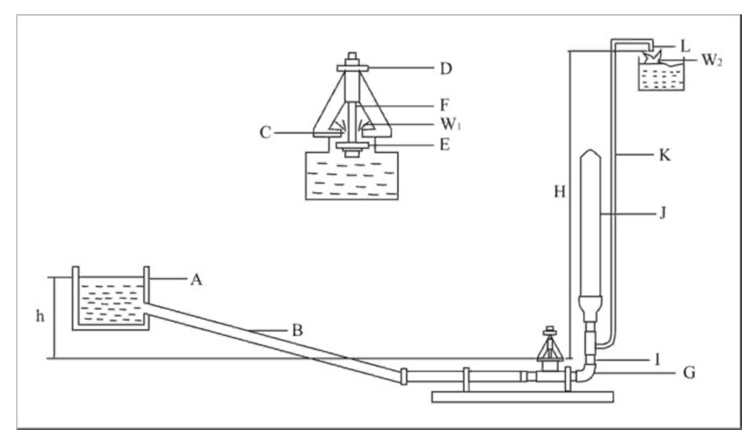

Gambar 1. Instalasi Hidraulik Ram (Sumber: Hanafie, 1979)

Keterangan : tempat yang lebih rendah ke tempat yang lebih tinggi dengan hasil guna tinggi dimana mampu mengalirkan air secara terus menerus (Hanafie, 1979). Pompa hidram mempunyai prinsip kerja memanfaatkan tekanan air yang jatuh. Pompa ini bekerja tanpa membutuhkan bahan bakar maupun listrik. Oleh karena itu, pompa ini cocok diaplikasikan di desa yang membutuhkan air dengan daya beli masyarakat terhadap bahan bakar yang rendah. Selain itu, pembuatan dan perawatan pompa ini sederhana serta suku cadangnya juga mudah diperoleh sehingga cocok untuk daerah dengan tingkat kemampuan teknis masyarakat yang terbatas.

Perbedaan geografis dan kebutuhan air menyebabkan konstruksi instalasi pompa hidram berbeda antara daerah satu dengan yang lainnya. Pada penelitian ini, dirancang instalasi pompa hidram yang sesuai dengan kondisi geografis Dusun Belang kemudian dianalisis karakter performanya.
A. Tangki pemasukan
B. Pipa pemasukan
C. Lubang katup limbah
D. Pemberat katup limbah
E. Katup limbah
F. Tangkai katup limbah
G. Lubang udara

H. Tinggi vertikal antara lubang katup limbah dengan lubang pengeluaran pipa penghantar

I. Katup udara

J. Ruang udara

K. Pipa penghantar

L. Lubang pengeluaran pipa penghantar

h. Tinggi vertikal antara permukaan air dalam tangki pemasukan dengan lubang katup limbah

$\mathrm{W}_{1}$. Debit air yang terbuang melalui katup limbah

$\mathrm{W}_{2}$. Debit pompa

Prinsip kerja pompa hidram merupakan proses perubahan energi kinetik aliran air menjadi tekanan dinamik dan sebagai akibatnya menimbulkan palu air (water hammer). Air mengalir dari suatu sumber atau sebuah tangki melalui pipa pemasukan dan keluar melalui katup limbah. Aliran air yang melalui katup limbah cukup cepat, maka tekanan dinamik yang merupakan gaya ke atas mendorong katup limbah sehingga tertutup secara tiba-tiba sambil menghentikan aliran air dalam pipa pemasukan. Aliran air yang terhenti mengakibatkan tekanan tinggi terjadi secara tiba-tiba dalam ram, jika 
tekanan cukup besar akan mengatasi tekanan dalam ruang udara pada katup penghantar dengan demikian membiarkan air mengaliri ruang udara dan seterusnya ke tangki penampungan.

Penentuan tinggi jatuh air dihitung menggunakan rumus :

$$
H=\frac{h \times q}{Q \times j}
$$

Pompa hidram dapat bekerja karena adanya peningkatan tekanan pada badan pompa. Peningkatan tekanan ini terjadi pada saat katup limbah menutup sehingga aliran air berhenti secara tiba-tiba. Pada saat yang sama, katup penghantar terbuka dan sebagian air masuk ke

Spesifikasi pompa hidram ditentukan berdasarkan besar debit air kebutuhan yang direncanakan. Perencanaan jumlah penyediaan air harus mengacu pada jumlah kebutuhan air perkapita perhari. Jumlah kebutuhan air total perhari didapatkan melalui perkalian antara jumlah penduduk dengan standar kebutuhan air perhari. Tingkat pemakaian air bersih secara umum ditentukan berdasarkan kebutuhan manusia untuk kehidupan sehari-hari. Kebutuhan manusia akan air dimulai dengan kebutuhan untuk air minum sampai pada kebutuhan untuk sanitasi.

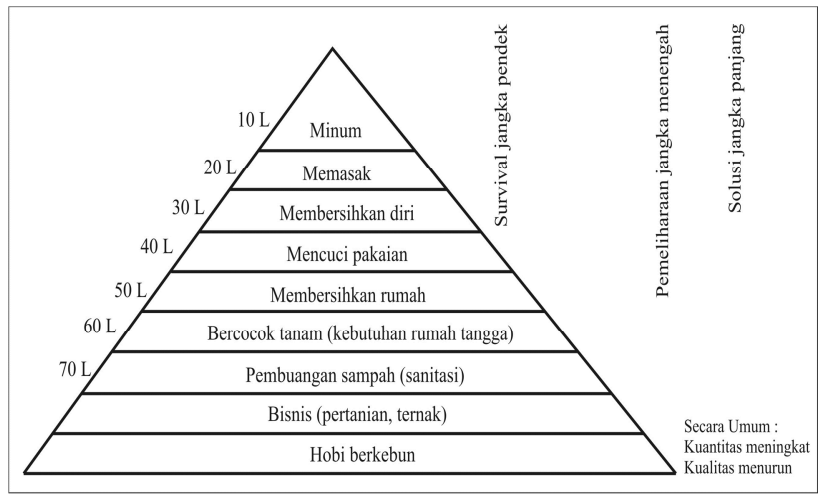

Gambar 2. Hirarki Kebutuhan Air

(Sumber: Reed, 2005)

\section{METODE PENELITIAN}

Model penelitian ini adalah Research and Development ( $\mathrm{R} \& \mathrm{D})$. Penelitian ini mengembangkan pompa hidram agar sesuai dengan topografi Desa Belang sehingga dapat bekerja secara optimal. Setelah instalasi terpasag dengan baik, kemudian dikaji performa pompa hidram tersebut. dalam pipa udara. Besarnya kenaikan tekanan yang terjadi pada badan pompa dihitung menggunakan persamaan :

$$
\Delta H p=\stackrel{(\quad)}{\longrightarrow}
$$

Efisiensi pompa hidram menyatakan perbandingan antara debit air yang keluar dari katup limbah dengan debit air pada pipa penghantar. Efisiensi pompa hidram dapat ditentukan menggunakan rumus Rankine. Pada rumus Rankine, dimasukkan selisih tinggi jatuh dan tinggi pemompaan dalam rumus efisiensi. Hal ini berarti Rankine menggunakan tinggi permukaan air pada bak pemasukan sebagai datum, sehingga persamaan efisiensi pompa menurut Rankine adalah :

$$
=\frac{(\quad)}{(\quad)}
$$

Studi awal penelitian terdiri atas studi lapangan dan studi pustaka. Studi pustaka dilakukan melalui eksplorasi pustaka mengenai sistem kerja pompa hidram dan pengembanganpengembangan pompa hidram yang sudah ada. Studi lapangan dilakukan di Dusun Belang Boyolali mengingat rancangan pompa akan diimplementasikan di daerah ini. Studi lapangan ditujukan untuk mendapatkan tinggi jatuh air dari mata air sumber ke pompa hidram, tinggi bak penampung serta debit mata air yang tersedia yang kemudian digunakan untuk merancang pompa dengan tepat.

Data spesifikasi pompa yang didapat kemudian diplot dalam bentuk gambar teknik. Tahap ini merupakan pengerjaan detail rancangan dalam bentuk gambar lengkap dan daftar komponen spesifikasi bahan, toleransi dan lain sebagainya. Spesifikasi bahan secara keseluruhan merupakan hal yang penting dalam pembuatan alat. Karakteristik yang dimunculkan harus memenuhi aspek biaya, topografi, dan performa pompa. Pada fase ini semua pekerjaan didokumentasikan sehingga pembuatan produk dapat dilaksaanakan oleh teknisi bengkel yang ditunjuk.

Komponen pompa hidram yang dibuat di bengkel dipasang pada komponen instalasi pompa di lapangan. Lokasi instalasi pompa hidram ditentukan pada tempat yang bebas dari ancaman banjir lahar dingin dimana data ini diperoleh saat studi awal penelitian. Tahap ini terdiri atas pemasangan pipa penghantar sesuai jalur yang telah ditentukan serta setting pompa hidram dengan bak penampung. Pengecekan (troubleshooting) dilakukan sebelum memasuki 
tahap pengambilan data agar tidak banyak kendala yang muncul saat data diambil.

Pengujian di lapangan dilakukan untuk mendapatkan informasi kinerja pompa hidram saat beroperasi. Metode yang dipilih untuk mengetahui kinerja pompa adalah dengan memvariasikan panjang langkah katup limbah serta variasi beban katup limbah. Data yang diambil merupakan data kuantitatif yang meliputi debit air pada katup limbah $(Q)$, jumlah ketukan katup limbah serta debit air pada pipa penghantar $(q)$. Pengambilan data pada masingmasing percobaan dilakukan sebanyak tiga kali, kemudian dihitung nilai rata-ratanya. Pada tahap analisis dan interprestasi hasil dilakukan analisis kinerja pompa hidram. Teknik analisis yang digunakan merupakan analisis deskriptif kualitatif.

\section{HASIL DAN PEMBAHASAN}

Perancangan pompa hidram dilakukan dengan mempertimbangkan kebutuhan air masyarakat. Proyeksi kebutuhan air penduduk Dusun Belang dihitung berdasarkan diagram hierarki kebutuhan air menurut Reed (2005).

Dusun Belang dihuni oleh 57 Kepala Keluarga dan terdiri atas 195 jiwa, sehingga besar kebutuhan airnya didapatkan melalui perkalian antara standar kebutuhan air menurut Reed dengan jumlah penduduk Dusun Belang. Standar kebutuhan air antara orang dewasa dengan anak-anak diasumsikan sama sehingga secara teoretis, kebutuhan air penduduk Dusun Belang secara keseluruhan dapat dilihat pada Tabel 1.

Tabel 1. Proyeksi Kebutuhan Air Penduduk Dusun Belang per Hari

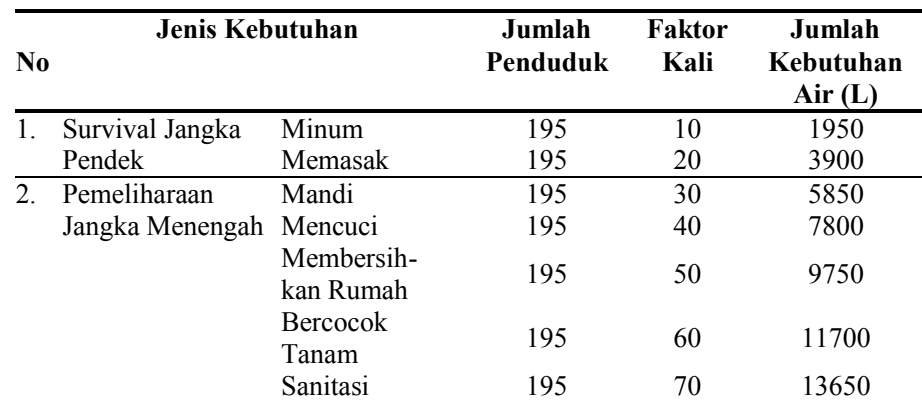

Tabel 1. menunjukkan kebutuhan air penduduk yang disusun berdasarkan tingkat prioritas pemenuhan kebutuhan air sehari-hari. Hal ini berarti jenis kebutuhan air pada item no. 2. sudah mencakup kebutuhan air pada item no. 1. Kebutuhan air pada subitem b. dipenuhi setelah kebutuhan air pada subitem a. terpenuhi.

Pada praktiknya, kebutuhan air di lapangan dapat lebih rendah dari kebutuhan air standar. Hal ini disebabkan budaya masyarakat setempat yang cenderung lebih hemat dalam memenuhi kebutuhan air harian seperti mandi dan mencuci.

Perancangan instalasi pompa hidram dilakukan berdasarkan data yang diperoleh dari lapangan, sehingga dihasilkan kebutuhan perancangan awal berupa data-data sebagai berikut :

a. Kebutuhan air harian penduduk Dusun

Belang ditentukan berdasarkan proyeksi

kebutuhan air pada Tabel 4.1. (13650

L/hari). b. Mata air yang digunakan adalah mata air Kali Belik dengan debit air pipa supply sebesar 300 L/menit (432000 L/hari).

c. Ketinggian bak penampungan terhadap lokasi pompa hidram (head keluar) sebesar 80 meter dengan jarak distribusi sejauh 400 meter.

Berdasarkan data penelitian awal yang didapatkan dari lapangan, diputuskan beberapa parameter seperti Tabel 2. sebagai berikut:

Tabel 2. Parameter Pompa Hidram

\begin{tabular}{lc}
\hline \multicolumn{1}{c}{ Variabel } & Ukuran \\
\hline Head Masuk $(\mathrm{H})$ & $4,5 \mathrm{~m}$ \\
Head Keluar $(\mathrm{h})$ & $80 \mathrm{~m}$ \\
Panjang Pipa Pemasukan & $18 \mathrm{~m}$ \\
Diameter Pipa Pemasukan & 4 inci \\
Diameter Pipa Penghantar & $1 \mathrm{inci}$ \\
Diameter Katup Limbah & $80 \mathrm{~mm}$ \\
\hline
\end{tabular}

Karakteristik pompa hidram dapat ditentukan dengan mengatur posisi katup limbah 
pada nilai tertentu. Pengaturan katup limbah dilakukan dengan memvariasikan berat dan panjang langkah katup limbah. Hal ini bertujuan untuk memperoleh pengaturan pompa hidram yang mempunyai kinerja paling optimal. Debit air yang tersedia bukan bagian dari variabel pengujian, namun hanya menjadi salah satw kondisi persyaratan pada aplikasi di lapangan. Pengaturan katup limbah akan mempengaruhi kinerja pompa hidram sebagai berikut :

a. Efisiensi Rankine akan meningkat beberapa saat namun akhirnya akan menurun ketika beban katup limbah bertambah besar (efisiensi Rankine akan berada dalam kondisi optimal pada tingkat beban tertentu).

b.Debit air pada pipa penghantar akan meningkat beberapa saat namun akhirnya akan menurun ketika beban katup limbah bertambah besar (debit air pipa penghantar akan berada dalam kondisi optimal pada tingkat beban tertentu).

PTP-ITB dalam Cahyanta dan Indrawan (1996) mengemu-kakan hasil penelitian bahwa beban katup limbah berpengaruh terhadap efisiensi pompa hidram. Penelitian ini menunjukkan bahwa efisiensi pompa terbesar diperoleh pada beban katup limbah 400 gram yaitu $42,92 \%$. Pengujian pompa hidram pada penelitian ini dilakukan dengan memvariasikan beban katup limbah sebanyak 4 variasi serta panjang langkah katup sebanyak 4 variasi. Pengambilan data dilakukan sebanyak tiga kali pada masing-masing variasi kemudian ditentukan nilai rata-ratanya.

Tabel 3. Parameter Pengujian

\begin{tabular}{|c|c|}
\hline Variabel & Ukuran \\
\hline Beban Katup Limbah & $\begin{array}{c}0,250,500 \text { dan } 750 \\
\text { gram }\end{array}$ \\
\hline $\begin{array}{l}\text { Panjang Langkah } \\
\text { Katup }\end{array}$ & $20,25,30$ dan $35 \mathrm{~mm}$ \\
\hline
\end{tabular}

Pengujian pompa hidram dilakukan dengan jeda waktu 15 menit antara satu variasi dengan variasi yang lain. Hasil pengujian ditampilkan pada tabel berikut.

Tabel 4. Hasil Pengujian dengan Panjang Langkah Katup $20 \mathrm{~mm}$

\begin{tabular}{ccccc}
\hline $\begin{array}{c}\text { Berat } \\
\text { Katup } \\
\text { (gram) }\end{array}$ & $\begin{array}{c}\text { Debit Pipa } \\
\text { Penghantar } \\
\text { (L/menit) }\end{array}$ & $\begin{array}{c}\text { Debit } \\
\text { Katup } \\
\text { Limbah }\end{array}$ & $\begin{array}{c}\text { Efisiensi } \\
\text { Rankine } \\
(\boldsymbol{\eta})\end{array}$ & $\begin{array}{c}\text { Ketukan } \\
\text { Katup } \\
\text { (/menit) }\end{array}$ \\
\hline 0 & 0,647009 & 63,17656 & 0,170107 & 86 \\
250 & 0,879841 & 71,74244 & 0,203295 & 84 \\
500 & 1,399353 & 89,56554 & 0,258134 & 82 \\
750 & 2,214363 & 105,8897 & 0,343715 & 82 \\
\hline
\end{tabular}

Tabel 5. Hasil Pengujian dengan Panjang Langkah Katup $25 \mathrm{~mm}$

\begin{tabular}{ccccc}
$\begin{array}{c}\text { Berat } \\
\text { Katup } \\
\text { (gram) }\end{array}$ & $\begin{array}{c}\text { Debit Pipa } \\
\text { Penghantar } \\
\text { (L/menit) }\end{array}$ & $\begin{array}{c}\text { Debit } \\
\text { Katup } \\
\text { Limbah }\end{array}$ & $\begin{array}{c}\text { Efisiensi } \\
\text { Rankine } \\
(\boldsymbol{\eta})\end{array}$ & $\begin{array}{c}\text { Ketuka } \\
\mathbf{n} \\
\text { Katup } \\
(/ \mathbf{m e n i} \\
\mathbf{t})\end{array}$ \\
\hline 0 & 1,961507 & 95,6654 & 0,337142 & 80 \\
250 & 2,150711 & 105,6068 & 0,334909 & 81,33 \\
500 & 2,895426 & 124,9242 & 0,380108 & 78 \\
750 & 3,067196 & 136,2778 & 0,369353 & 78 \\
\hline
\end{tabular}

Tabel 6. Hasil Pengujian dengan Panjang Langkah Katup $30 \mathrm{~mm}$

\begin{tabular}{ccccc}
\hline $\begin{array}{c}\text { Berat } \\
\text { Katup } \\
\text { (gram) }\end{array}$ & $\begin{array}{c}\text { Debit Pipa } \\
\text { Penghantar } \\
\text { (L/menit) }\end{array}$ & $\begin{array}{c}\text { Debit } \\
\text { Katup } \\
\text { Limbah }\end{array}$ & $\begin{array}{c}\text { Efisiensi } \\
\text { Rankine } \\
(\boldsymbol{\eta})\end{array}$ & $\begin{array}{c}\text { Ketukan } \\
\text { Katup } \\
\text { (/menit) }\end{array}$ \\
\hline 0 & 5,301964 & 194,4178 & 0,445459 & 73,3333 \\
250 & 6,746969 & 225,892 & 0,486652 & 72 \\
\hline 500 & 7,197461 & 251,859 & 0,466205 & 69,3333 \\
750 & 7,319224 & 267,6515 & 0,446653 & 66 \\
\hline
\end{tabular}

Tabel 7. Hasil Pengujian dengan Panjang Langkah Katup $35 \mathrm{~mm}$

\begin{tabular}{|c|c|c|c|c|}
\hline $\begin{array}{l}\text { Berat } \\
\text { Katup } \\
\text { (gram) }\end{array}$ & $\begin{array}{c}\text { Debit Pipa } \\
\text { Penghanta } \\
\text { r } \\
\text { (L/menit) }\end{array}$ & $\begin{array}{c}\text { Debit } \\
\text { Katup } \\
\text { Limbah }\end{array}$ & $\begin{array}{c}\text { Efisiensi } \\
\text { Rankine } \\
(\eta)\end{array}$ & $\begin{array}{c}\text { Ketuk } \\
\text { an } \\
\text { Katu } \\
\text { p } \\
(/ \mathbf{m e n} \\
\text { it })\end{array}$ \\
\hline 0 & 7,277977 & $\begin{array}{c}247,000 \\
6\end{array}$ & 0,480278 & $\begin{array}{c}70,66 \\
67\end{array}$ \\
\hline 250 & 7,186046 & $\begin{array}{c}277,628 \\
7\end{array}$ & 0,423369 & 68 \\
\hline 500 & 7,261164 & 299,341 & 0,397396 & $\begin{array}{c}66,66 \\
67\end{array}$ \\
\hline 750 & 7,522211 & $\begin{array}{c}323,780 \\
7\end{array}$ & 0,380989 & $\begin{array}{c}65,33 \\
33\end{array}$ \\
\hline
\end{tabular}

Pengujian pompa hidram dengan panjang langkah katup limbah $20 \mathrm{~mm}$ menghasilkan debit pipa penghantar sebesar $0,647009 \mathrm{~L} /$ menit pada variasi beban minimum (tanpa penambahan beban). Debit air pada pipa penghantar mengalami peningkatan hingga pada variasi penambahan beban 750 gram dengan debit pipa penghantar sebesar 2,214363 L/menit. Efisiensi Rankine juga mengalami siklus yang sama seiring dengan penambahan beban pada katup limbah. Efisiensi minimum ditunjukkan oleh variasi beban minimum yaitu sebesar 0,170107 ; sedangkan efisiensi maksimum terjadi pada variasi beban 750 gram yaitu sebesar 0,343715 . Debit air pipa penghantar mengalami peningkatan selama penambahan beban katup limbah. Katup limbah yang bertambah berat menyebabkan periode ketukan katup membesar, hal ini berarti lebih banyak air yang keluar dari katup limbah. 


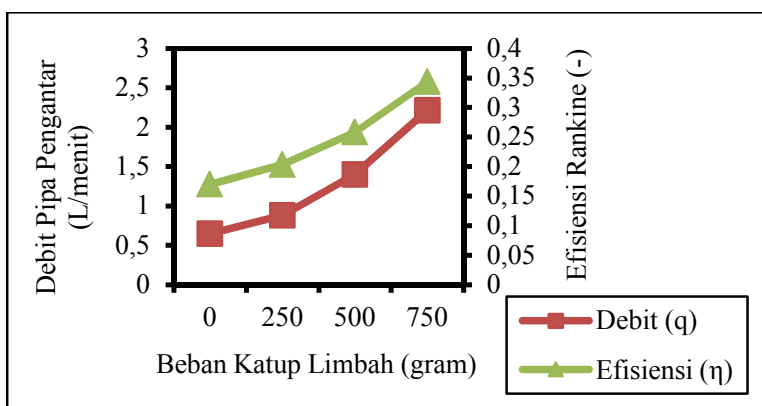

Gambar 3. Hubungan Beban Katup Limbah dengan Debit Pipa Penghantar (q) dan Efisiensi Rankine ( $\eta$ ) pada Jarak Langkah Katup 20 mm

Pengujian pompa hidram dengan panjang langkah katup limbah $25 \mathrm{~mm}$ menghasilkan debit pipa penghantar sebesar 1,961507 L/menit pada variasi beban minimum. Debit air pada pipa penghantar selalu mengalami peningkatan hingga variasi penambahan beban 750 gram dengan debit pipa penghantar mencapai 3,067196 L/menit. Efisiensi Rankine pada beban minimum menunjukkan angka 0,337142 dan mengalami penurunan pada tingkat beban 250 gram menjadi 0,334909. Penurunan efisiensi Rankine dari variasi tanpa beban ke 250 gram tidak terlalu signifikan. Penurunan efisiensi dipengaruhi oleh peningkatan debit air pada katup limbah yang tidak sebanding dengan debit air pada pipa penghantar. Efisiensi Rankine kemudian mengalami peningkatan pada tingkat beban 500 gram dan menurun kembali pada tingkat beban 750 gram. Efisiensi pompa cenderung bersifat fluktuatif selama penambahan beban pada katup limbah. Peningkatan debit air pada pipa penghantar yang cukup signifikan terjadi pada penambahan beban 250 gram menjadi 500 gram. Efisiensi Rankine juga mengalami peningkatan yang cukup besar pada fase ini.

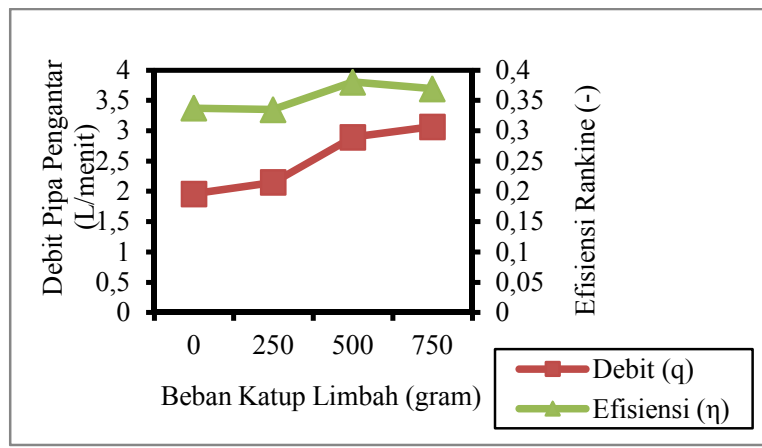

Gambar 4. Hubungan Beban Katup Limbah dengan Debit Pipa Penghantar (q) dan Efisiensi Rankine ( $\eta$ ) pada Jarak Langkah Katup 25 mm
Pengujian pompa hidram dengan panjang langkah katup limbah $30 \mathrm{~mm}$ menghasilkan debit pipa penghantar sebesar 5,301964 L/menit pada variasi beban minimum. Debit air pada pipa penghantar selalu mengalami peningkatan hingga variasi penambahan beban 750 gram dengan debit pipa penghantar sebesar 7,319224 $\mathrm{L} / \mathrm{menit}$. Efisiensi Rankine pada beban minimum menunjukkan angka 0,445459 dan mengalami kenaikan pada tingkat beban 250 gram menjadi 0,486652. Efisiensi Rankine mulai mengalami penurunan saat beban katup limbah semakin besar hingga mencapai 0,446653 pada tingkat beban 750 gram. Efisiensi akan terus menurun seiring bertambahnya beban pada katup limbah. Grafik hubungan antara berat beban katup limbah-debit penghantar (q) serta beban katup limbah-efisiensi Rankine $(\eta)$ pada jarak langkah katup $30 \mathrm{~mm}$ dapat dilihat pada Gambar 5.

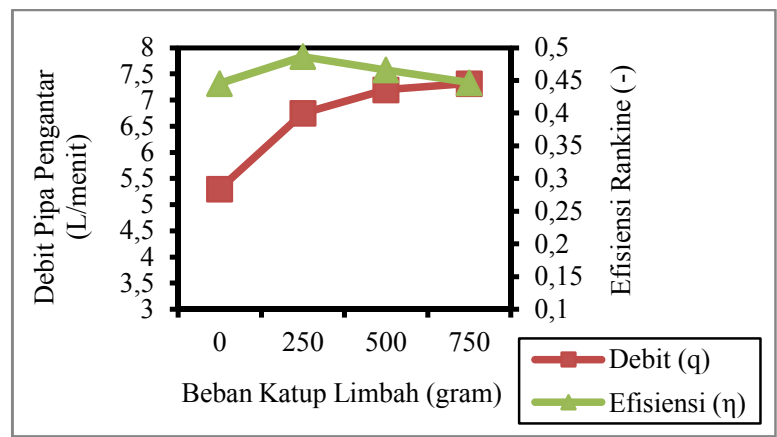

Gambar 5. Hubungan Beban Katup Limbah dengan Debit Pipa Penghantar (q) dan Efisiensi Rankine ( $\eta$ ) pada Jarak Langkah Katup $30 \mathrm{~mm}$

Pengujian pompa hidram dengan panjang langkah katup limbah $35 \mathrm{~mm}$ menghasilkan debit pipa penghantar sebesar 7,277977 L/menit pada variasi beban minimum. Debit air pada pipa penghantar sedikit menurun pada variasi beban 250 gram yaitu mencapai 7,186046 L/menit. Debit air pada pipa penghantar kemudian mengalami peningkatan hingga variasi beban 750 gram dengan debit pipa penghantar sebesar 7,522211 L/menit. Efisiensi Rankine pada beban minimum menunjukkan angka 0,480278 dan mengalami penurunan seiring dengan penambahan beban pada katup limbah. Efisiensi paling rendah terjadi pada tingkat beban 750 gram dengan efisiensi 0,380989 . Grafik hubungan antara berat beban katup limbah-debit penghantar (q) serta beban katup limbah-efisiensi Rankine $(\eta)$ pada jarak langkah katup $35 \mathrm{~mm}$. 


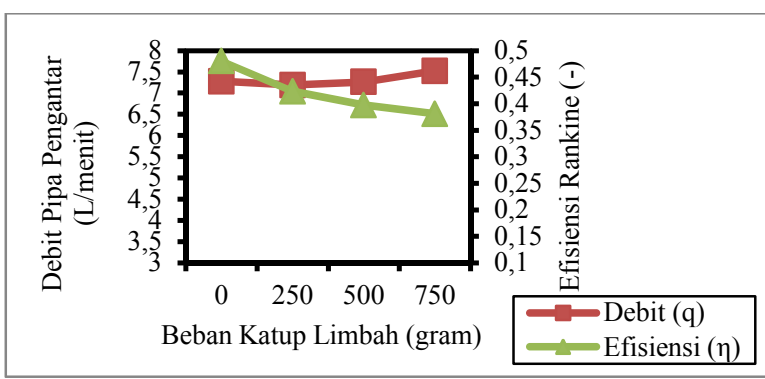

Gambar 6. Grafik Hubungan Beban Katup Limbah dengan Debit Pipa Penghantar (q) dan Efisiensi Rankine ( $\eta$ ) pada Jarak Langkah Katup 35 mm

Efisiensi pompa hidram yang paling tinggi ditunjukkan pada percobaan panjang langkah katup limbah $30 \mathrm{~mm}$ dan beban 250 gram dengan nilai 0,486652 ( $q=6,746969 \mathrm{~L} /$ menit) sedangkan debit air pada katup penghantar yang paling tinggi ditunjukkan pada percobaan panjang langkah katup limbah $35 \mathrm{~mm}$ dan beban 750 gram dengan nilai $7,522211 \mathrm{~L} /$ menit $(\eta=$ 0,380989). Pengaturan pompa hidram dapat dilakukan pada kondisi debit maksimal jika debit air pada bak pemasukan mencukupi, namun jika debit air pada bak pemasukan berada dalam kondisi terbatas, pengaturan pompa hidram dapat dilakukan pada tingkat efisiensi maksimum.

Pompa hidram dengan debit pipa penghantar maksimum dapat menghasilkan debit air sebesar 7,522211 L/menit, sedangkan pengaturan pompa pada efisiensi maksimum dapat menghasilkan debit air sebesar 6,746969 L/menit. Pompa hidram dapat bekerja selama 24 jam nonstop, sehingga debit air yang dihasilkan dalam satu hari dapat mencapai 10831,98384 L pada pengaturan debit maksimum dan 9715,63536 L pada pengaturan efisiensi maksimum. Menurut Tabel 1. besar debit yang dihasilkan oleh pompa hidram dapat memenuhi kebutuhan air penduduk hingga level pemeliharaan jangka menengah spesifikasi jenis kebutuhan membersihkan rumah. Hal ini berarti pompa hidram dapat memenuhi kebutuhan air untuk minum, memasak, mandi, mencuci serta membersihkan rumah.

\section{KESIMPULAN}

Berdasarkan analisis data dan pembahasan penelitian yang dilakukan, dapat ditarik kesimpulan sebagai berikut :

1. Kebutuhan air penduduk Dusun Belang mencapai 3900 Liter/ hari untuk jenis kebutuhan survival jangka pendek dan 13650 Liter/ hari untuk pemeliharaan jangka menengah dengan jumlah penduduk 195 jiwa.

2. Perancangan instalasi pompa hidram untuk aplikasi di Dusun Belang menghasilkan parameter rancangan; head masuk 4,5 meter, head keluar 80 meter, diameter pompa ratarata 4 inci dengan panjang pipa penghantar 18 meter.

3. Efisiensi pompa hidram yang paling tinggi ditunjukkan pada percobaan panjang langkah katup limbah $30 \mathrm{~mm}$ dan beban 250 gram dengan nilai 0,486652 ( $\mathrm{q}=6,746969 \mathrm{~L} / \mathrm{menit})$ sedangkan debit air pada katup penghantar yang paling tinggi ditunjukkan pada percobaan panjang langkah katup limbah 35 $\mathrm{mm}$ dan beban 750 gram dengan nilai 7,522211 L/menit $(\eta=0,380989)$.

4. Pompa hidram dapat memenuhi kebutuhan air penduduk hingga level pemeliharaan jangka menengah spesifikasi jenis kebutuhan membersihkan rumah, yaitu dengan debit kebutuhan 9750 Liter/ hari.

\section{DAFTAR PUSTAKA}

Cahyadi, Agung Dwi. (2011). Warga Kota Sulit Akses Air Bersih. http://nationalgeographic.co.id/lihat/berita/801/warga-kota-sulit-akses-air-bersih diakses pada 7 Mei 2013.

Cahyanta, Y. A. dan Indrawan. (1996). "Studi Terhadap Prestasi Pompa Hydraulic Ram Dengan Variasi Beban Katup Lim-bah." Jurnal Ilmiah Teknik Mesin Cakram.

Hanafie, J. (1979). Teknologi Pompa Hidraulik Ram. Bandung: Pusat Teknologi Pembangunan Institut Teknologi Bandung.

Prihatin, Rohani Budi. (2013). Problem Air Bersih di Perkotaan. Jurnal Info Singkat, Vol. 5. April 2013: 9-12. Pusat Pengkajian, Pengolahan Data dan Informasi Sekretariat Jenderal DPR RI.

Reed, B. J. (2005). Minimum Water Quantity Needed for Domestic Uses. Leichestershire: Water Engineering and Development Centre Loughborough University. 
Zoller, F., J. Woudstra dan M. Van der Wiel. (2006). Hydraulic Ram Pumping in Rural Community Development. Durban: Rijswijk University of Professional Technical Education, the Netherlands and Biogas Technology Africa CC. 